\title{
9.Sınıf Matematik Ders Kitabındaki Üçgenler Ünitesinin Çoklu Temsiller Bağlamında İncelenmesi
}

\section{Examining the Triangles Unit in the 9th Grade Mathematics Textbook in the Context of Multiple Representations}

\author{
Deniz EROĞLU , Burdur Mehmet Akif Ersoy Üniversitesi, Eğitim Fakültesi, deroglu@mehmetakif.edu.tr
}

Burcu AKKUŞ ${ }^{(D)}$, MEB, Burdur Gölhisar Anadolu Imam Hatip, burcualticek@hotmail.com

Eroğlu, D. ve Akkuş, B.(2021). 9.Sınıf Matematik Ders Kitabındaki Üçgenler Ünitesinin Çoklu Temsiller Bağlamında İncelenmesi. Batı Anadolu Eğitim Bilimleri Dergisi, 12(2), 786-804.

Öz. Bu araştırmanın amacı ortaöğretim 9. sınıf matematik ders kitabında üçgenler ünitesinde yer alan çözümlü ve çözümlü olmayan problemlerin çoklu temsil türlerinin incelenmesidir. Araştırmada ders kitabındaki problemler çoklu temsiller bağlamında incelendiğinden, doküman analizi yöntemi kullanılmıştır. Araştırma materyali olarak 2020-2021 eğitim-öğretim yılında tüm Türkiye'de fen liselerinde okutulan MEB yayınlarına ait "Ortaöğretim Fen Lisesi Matematik 9.sınıf Ders Kitabı" kullanılmışır. Araştırmanın verilerini ise, üçgenler ünitesinde yer alan çözümlü ve çözümlü olmayan problemler oluşturmaktadır. Ders kitabındaki problemler çoklu temsiller bağlamında içerik analizi kullanılarak incelenmiştir. Bulgular, çözümlü ve çözümsüz problemlerin girdi temsillerinde en çok şekil ve geometrik sembolik temsile yer verildiğini göstermiştir. Araştırma kapsamında incelenen diğer temsil türlerine ise -sözel, cebirsel sembolik ve günlük hayat bağlamı- çok az yer verildiği tespit edilmiştir. Çözümlü problemlerin çıktı temsillerinde ise en fazla geometrik sembolik ve cebirsel sembolik temsilin kullanıldığı, şekil temsiline ise az yer verildiği görülmüştür. Problemlerin içeriklerinde girdi temsili olarak günlük hayat temsiline çok az yer verilmesi, çözümlü problemlerde ise çıktı temsili olarak sözel temsilin çok az kullanılması bir eksiklik olarak düşünülebilir. Ders kitaplarında yer alan temsil çeşitliliğinin artırılması öğrencilerin matematiksel kavramları daha iyi anlamalarına yardımcı olacağından, ders kitabı yazarlarının gerekli düzenlemeleri yapmaları ve öğretmenlerin de ders kitaplarının çoklu temsil bakımından durumunu göz önüne alarak derslerini zenginleştirmeleri önerilmektedir.

Anahtar Kelimeler: Çoklu temsiller, Ortaöğretim matematik ders kitabı, Geometri, Üçgenler.

\begin{abstract}
The purpose of this study is to examine the types of multiple representations -as inputs and outputsof the solved and unsolved questions in the triangles section in the 9th grade mathematics textbook. Since the questions in the textbook were examined in the context of multiple representations, the research was carried out using document analysis. In the 2020-2021 academic year, "Secondary Education Science High School Mathematics 9th Grade Textbook" belonging to the MEB publications was used as the material of the research. The triangles unit in the book constitutes the data of the research. The solved and unsolved questions in the textbook were examined in the context of multiple representations using content analysis. Results showed that in the input representations of the solved and unsolved questions, figural and geometric symbolic representations were mostly included. It has been revealed that the number of other types of representationverbal, algebraic symbolic, and daily life context-is very few. In the output representations of the solved questions, however, it was observed that geometric symbolic and algebraic symbolic representations were used the most, and figural representation was used less frequently than them. When this situation is
\end{abstract}


considered as input representation, it is considered as a deficiency that daily life representations are rarely encountered in problems and verbal representations are rarely included in output representations.

Keywords: Multiple representations, Secondary school mathematics textbook, Geometry, Triangles. 


\section{Extended Abstract}

Introduction. Expressing a concept with different representations and making connections between them is seen as an important skill in mathematics education. When the literature is examined, it is seen that multiple representations are effective in revealing different meanings of mathematical concepts, and instruction designed using multiple representations can be very effective in improving students' scientific understanding. Textbooks are also seen as an important tool in mathematics education and the implementation of curricula, and in this context, representations that provide conceptual learning and association in mathematics and geometry gain importance in textbooks. Studies on textbooks focus on the recognition of textbooks, the way and frequency of use, the examination of the activities presented in the textbooks in different contexts, and the views of teachers on textbooks. In addition, there are PISA and TIMMS standards in textbooks and studies on representation in textbooks. It is seen that these researches are generally not carried out in the field of geometry. The geometry learning area is a field where visualization is at the forefront and shape representations are the most common representations used. However, in addition to the use of these multiple representations in geometry, performing multiple representation transitions is considered important to support students' understanding. In addition, textbooks are seen as the most important curriculum material that affects what happens in the classroom. Therefore, various multi-representation transitions in the textbooks will also affect the teaching and learning that takes place in the classroom. For this reason, the level of the use of multiple representations and multiple representation transitions in the triangles unit determined in the field of geometry was investigated. In this research, in order to examine the multiple representations in the textbook, input-output representations, external representation and 1. numbers-symbols, 2. verbal representations, 3. real life contexts, 4. manipulative representations and 5. picture, diagram and table representations types were used. The purpose of this study is to examine the types of multiple representations -as inputs and outputs- of the solved and unsolved questions in the triangles section in the 9th grade mathematics textbook.

Method. Since the questions in the textbook were examined in the context of multiple representations, the research was carried out using document analysis. In the 2020-2021 academic year, "Secondary Education Science High School Mathematics 9th Grade Textbook" belonging to the MEB publications was used as the material of the research. The triangles unit in the book constitutes the data of the research. The solved and unsolved questions in the textbook were examined in the context of multiple representations using content analysis.

Results. Results showed that in the input representations of the solved and unsolved questions, figural and geometric symbolic representations were mostly included. It has been revealed that the number of other types of representation-verbal, algebraic symbolic, and daily life context-is very few. In the output representations of the solved questions, however, it was observed that geometric symbolic and algebraic symbolic representations were used the most, and figural representation was used less frequently than them. When this situation is considered as input representation, it is considered as a deficiency that daily life representations are rarely encountered in problems and verbal representations are rarely included in output representations.

Discussion and Conclusion. According to the results of the research, it was seen that in the input representations of the solved and unsolved questions in the triangles unit of the 9th grade mathematics textbook, shape and geometric symbolic representations were mostly included. It has been determined that the other types of representation examined within the scope of the research verbal, algebraic symbolic and daily life context- are given very little place. In the output representations of the solved questions, it was seen that geometric symbolic and algebraic symbolic 
representations were used the most, and shape representation was used less frequently than them. The use of verbal representation in problem solving is not included at all.

According to another result of the research, the difference in the distribution of verbal representations in the case of input and output draws attention in the subject-based distribution of representations. It is seen that verbal representation is not included in output representation in all subject types. It is thought that this situation will create negativity on students who can make sense of the solution of the problem with a verbal expression. Another finding is that algebraic symbolic representation is used at a very low rate in the input representation and mostly included in the output representation. It is thought that this situation may lead students to a wrong perception that algebraic symbolic representation will only be used in solution. In addition, while the importance of the ability to relate mathematics to real life, which our curriculum and mathematics authorities mostly focus on, is known, as seen in the subject-based distribution, it is seen that the representation of the daily life context is limited in some subjects, and this situation is in contrast with the desired objectives of the curriculum. This situation reveals the lack of handling geometry subjects, which are quite suitable for associating with daily life, in the textbook.

Multiple representations offer opportunities to students in different ways in teaching each subject and concept. For this reason, it is important to know which representation types are more effective in learning which subjects and concepts with multiple representation studies to be carried out on different subjects. It is thought that such research results will also affect the book contents of multiple representations. In future studies, it is possible to deepen the research by taking student solutions and teacher opinions about multiple representations. It is thought that the authors of the textbooks can benefit from the results of this research and the proposed studies. Finally, it is thought that the present research results will draw the attention of mathematics teachers and textbook authors to the importance of the use of multiple representations and transitions between representations, and that the results of the research are valuable. 


\section{Giriş}

Günümüz dünyasında matematik dersinde kazanılan beceriler, yaşam becerisi olarak görülmeye başlanmıştır. Matematik eğitiminde otorite olarak görülen bazı kuruluşlar, öğrencilerin düşündüklerini aktarabildikleri ve kendi fikirlerini ortaya koyabilecekleri matematiksel iletişim becerisini kazanmaları gerektiğini belirtmektedir (National Council of Teachers of Mathematics [NCTM], 2000). Bu durum matematiği daha anlaşılabilir ve uygulanabilir kılmak için araştırmacıların yeni öğrenme araçları geliştirmelerine sebep olmuştur. Çoklu temsiller bu araçlardan bir tanesidir. Çoklu temsiller alan yazına 1923'te Amerikan Matematik Derneği'nin cebir ve geometride farklı temsillere yer vermenin anlamayı geliştireceğine dair raporuyla girmiştir ve çoklu temsillere değinen pek çok yaklaşım olduğu görülmektedir (Adu-Gyamfi, 2007). Bunlardan biri Dienes'ın (1960) "algısal çeşitlilik prensibi" yaklaşımıdır. Bu prensip matematiğin temelinde var olan soyut kavramların, onlara denk algısal eşdeğer yapılar ile sunulmasını öngörmektedir. Dienes'ın yaklaşımıyla, çoklu temsiller teori olarak matematik öğretim sürecinde yerini almıştır (Çıkla, 2004; Delice ve Sevimli, 2012).

Matematik eğitiminde bir kavramı farklı temsiller ile ifade edebilme ve bunlar arasında ilişkilendirme yapabilme önemli bir beceri olarak görülmektedir (National Council of Teachers of Mathematics (NCTM), 2000). Etkili matematik öğretiminde matematiksel kavram ve işlemlerin anlaşııması için öğrencilerin matematiksel temsiller arasında bağlantı kurmaları gerekliliğine vurgu yapılmaktadır (Hiebert ve Carpenter, 1992; NCTM, 2014). Diğer bir deyişle, öğrenciler temsille ilgilendikçe ve temsiller arası bağlantılar aracılı̆ııyla düşüncelerini ifade edip gerekçelendirdikçe, daha derin kavramsal anlayışlar sergilemektedirler (Fuson, Kalchman ve Bransford, 2005). Matematiksel bilgiyi kavramsal olarak yapılandırmada (Ainsworth, 2006); matematiksel kavramların farklı anlamlarını ortaya çıkarmada ve öğretimlerde öğrencilerin bilimsel anlayışlarını geliştirmede çoklu temsillerin etkili olduğu görülmektedir (Adadan, 2013; Kaput, 1992). Hatta öğretmenlerin temsilleri ve temsiller arası geçişleri öğretimlerde kullanmalarının, öğrencilerin matematiği anlama ve matematikte başarılı olma durumlarını artırdığı ifade edilmektedir (Gagatsis ve Shikalli, 2004).

Bu araştırmada 9. sınıf matematik ders kitabındaki üçgenler ünitesinde yer alan problemlerin çoklu temsil türleri bakımından incelemesi gerçekleştirilmiştir. Matematik öğretim programında geometri büyük bir yer kaplamakta ve temsiller de geometri içeriğinde çok fazla yer almaktadır. Geometri fiziksel dünyayı anlama yollarından biri olarak görüldüğünden, öğretim programlarında geniş yer bulmaktadır (Tekin, 2007). Öğretimlerde kullanılan temsil çeşitlerinin ve temsiller arası geçişlerin, öğrencilerin farklı matematik kavramlar arasında bağlantı kurmalarına ve kavramlar arası ilişkileri anlamalarına yardımcı olduğu belirtilmiştir (Anthony ve Walshaw, 2009; Konyalıoğlu, 2003). Ayrıca temsil kullanma becerilerini geliştiren öğrencilerin matematikte problem çözme başarılarında da gelişmeler görüldüğü ifade edilmiştir (Hwang, Chen, Dung, \& Yang, 2007). Ders kitapları da matematik eğitiminde ve öğretim programlarının uygulanmasında önemli bir araç olarak görülmekte, bu bağlamda geometride kavramsal öğrenmeyi ve ilişkilendirmeyi sağlayan temsillerin ders kitaplarındaki yeri de önem kazanmaktadır (Johanson, 2003). Ders kitapları öğrenciler için pek çok matematik öğrenme fırsatı sunduğundan, 1990 yılı sonrasında farklı ülkelerin ders kitaplarının analizine odaklanan pek çok araştırma gerçekleştirilmiştir (Özer ve Sezer, 2014). Ders kitapları üzerine yapılan çalışmalar ders kitaplarının tanınması, kullanım şekli ve sıkığı (Altun, Arslan ve Yazgan, 2004; Işık, 2008; Taşdemir, 2011), ders kitaplarında sunulan etkinliklerin farklı bağlamlarda incelenmesi ve ders kitapları üzerine öğretmen görüşleri (Arslan ve Özpınar, 2009; Baştürk, 2007; Kerpiç ve Bozkurt, 2011; Şahin ve Turanlı, 2005; Uğurel, Bukova-Güzel ve Kula, 2010) üzerine yoğunlaşmaktadır. Ayrıca ders kitaplarında PISA ve TIMMS standartları (İskenderoğlu ve Baki, 2011; Şaban, 2019) ve ders kitaplarında temsil kullanımı (İncikabı, 2017; İncikabı ve Biber, 2018; Karakuzu, 2017) ile ilgili çalışmalar da mevcuttur. Alan-yazında çoklu temsillerle ilgili araştırmalar öğrenme alanı açısından incelendiğinde, sıklıkla cebir öğrenme alanı üzerine yoğunlaşıldığı görülmekte ve ders kitaplarında 
geometri alanının çoklu temsiller bakımından incelenmesiyle ilgili bir boşluğun olduğu göze çarpmaktadır.

Geometri öğrenme alanı görselleştirmenin ön planda olduğu bir alandır ve şekil temsili geometride kullanılan en yaygın temsillerden biridir. Ancak geometride çoklu temsil kullanımının yanında, çoklu temsil geçişlerinin gerçekleştirilmesi öğrencilerin anlamalarını desteklemek için önemli görülmektedir. Bununla birlikte, geometri günlük hayat temsillerinin kullanımı için de pek çok fırsatlar sunmaktadır. Yang, Tseng ve Wang (2017) dört farklı ülkede okutulan matematik kitaplarındaki geometri problemlerinde açık uçlu ve gerçek hayat problemlerine çok az yer verildiğini ortaya koymuş ve bu türdeki problemlerin kitaplarda daha fazla yer alması gerekliliğine vurgu yapmıştır. Ayrıca ders kitapları matematik öğretimini etkileyen en önemli kaynaklardan biri olarak görülmektedir (Fan, 2013; Kilpatrick, Swafford ve Findell, 2001). Dolayısıyla ders kitaplarında yer alacak çeşitli çoklu temsil geçişleri de sınıf içinde gerçekleşen öğretim ve öğrenmeleri de etkileyecektir. Bu nedenle bu araştırmada bir matematik ders kitabının üçgenler ünitesinde yer alan çoklu temsil türlerinin hangi oranda var olduğu araştırılmıştır.

\section{Kavramsal Çerçeve}

Bu araştırmada ders kitabında yer alan çoklu temsilleri incelemek için Goldin ve Kaput'un (1996) tanımlamış olduğu dış temsil; Kendall'ın (2002) tanımlamış olduğu girdi-çıktı temsilleri, ve Lesh, Post ve Behr'in (1987) 1. sayılar-semboller, 2.sözlü temsiller, 3.gerçek hayat bağlamları, 4. manipülatif temsiller ve 5.resim, diyagram ve tablo temsilleri olarak sınıflandırdığı çoklu temsil türlerinden yararlanılmıştır.

Bir matematiksel objenin birden çok temsili vardır ve öğrencilerin kavramsal anlayış geliştirebilmeleri için temsiller arasındaki ilişkilerin kurulması önemlidir (Hiebert ve Carpenter, 1992). Bu sebeple farkı eğitimciler temsillerin farklı yönlerini ele alarak birçok farklı tanımlama yapmışlardır. Duval (2006) matematiksel nesneler doğrudan erişilebilir olmadığından, uzmanların ve öğrencilerin bu nesnelerle uğraşırken temsilleri kullandıklarını ifade etmiştir. "Temsil" kavramı matematiksel nesneleri temsil eden şeyler anlamında kullanılmaktadır (Duval, 2006; Goldin \& Shteingold, 2001). Delice ve Sevimli (2016) ise temsili matematiksel nesnelerin zihinde işlenebilmesi ve başka kişilere aktarılabilmesi için kullanılan araçlar olarak tanımlamaktadırlar. Çoklu temsil kullanımında, matematiksel kavramların sözel, grafiksel ya da sembolik olarak çeşitli temsillerle ifade edilmesi ve öğrencilerin aynı matematiksel kavrama farklı şekillerde maruz bırakılması söz konusudur (Prain ve Waldrip, 2010). Bu temsil tanımlamalarında "bir kavramın farklı gösterimlerle sunulması" durumu ortak olarak yer almaktadır.

Çoklu temsillerin tanımı gibi sınıflandırılmasında da çeşitli yaklaşımlar söz konusudur. Goldin ve Kaput (2013) çoklu temsilleri iç temsiller ve dış temsiller olmak üzere 2 sınıfta incelemiştir. İ̧̧ temsiller, öğrencilerin zihinlerinde var olan durumu temsil ederken, dış temsiller ise bunun gözlemlenebilir dışa vurumunu yani öğrencilerin oluşturdukları temsilleri ifade etmektedir. Bu araştırmada da ders kitabı incelemesi söz konusu olduğundan, iç/zihinsel temsillerin kullanımı söz konusu değildir. Bu sınıflandırmaya ek olarak, girdi ve çıktı temsilleri (Kendall, 2002) olmak üzere iki farklı sınıflandırma yapılmıştır. Girdi temsillerinde problem çözümünde verilenlerin betimlendiği temsiller kastedilirken, çıktı temsillerinde ise problemin çözümünde ortaya çıkan kavramın temsil ile ilişkili olan anlamı ifade edilmektedir. Son olarak temsil sınıflamasında Lesh, Post ve Behr'in (1987) dönüşüm modeli olarak adlandırdığı temsil sistemi yer almaktadır. Bu sistem beş unsurdan oluşmaktadır. İlki matematiksel kavramları ifade etmek için sayılar veya semboller gibi yazılı sembolik temsillerdir. İkinci temsil türü, matematik kavramlarının kelimelerle ifade edildiğini gösteren sözlü temsillerdir. Bu temsil türü kelimelerin daha farklı şekillerde ifade edilmesine ve kavramların diğer alanlara ve yaşam durumlarına bağlanmasına izin vermektedir. Üçüncü temsil türü matematik 
kavramlarına uyan gündelik yaşam olaylarını kullanan ve bu olayların deneyimlere bağlı yorumlanması sonucu ortaya konan günlük hayat bağlamlarıdır. Dördüncü temsil türü öğrencilerin elle tutabileceği manipülatif temsiller ve modellerdir. Sınıflamada yer alan son temsil türü ise resimler, çizimler, diyagramlar ve tablolar olarak ele alınmıştır (Nahakara, 2008).

Bu temsil sınıflamaları ve ders kitabının yapısı göz önünde bulundurularak, bu araştırmada ders kitabında yer alan etkinlikler, dışsal temsil başlığı altında girdi ve çıktı temsili olarak iki kategoride ele alınmıştır. Ortaöğretim düzeyinde okutulan ders kitapları incelendiğinde, ders kitaplarının genellikle problemlerden ve tanımlamalardan oluştuğu görülmektedir. Kitabın içinde yer alan problemler çözümlü ise problemin içeriğinde yer alan temsil girdi temsili, çözümünde yer alan temsil çıktı temsili; problem çözümlü değil ise problemin yazımında kullanılan temsil girdi temsili olarak incelenmiştir. Bu sınıflamanın ardından Lesh, Behr ve Post'un (1987) oluşturduğu ve yukarıda açıklanan temsil sınıflamasından yararlanıımıştır.

\section{Çoklu Temsiller Üzerine Yapılmış Araştırmalar}

Ülkemizde çoklu temsil üzerine yapılan çalışmalar, öğrencilerin ve öğretmen adaylarının temsil kullanma düzeyleri üzerine yoğunlaşmaktadır (Baştürk, 2010; Çelik ve Sağlam-Arslan, 2012; Delice ve Sevimli, 2010; Yeşidere-Imre, Akkoç ve Baştürk-Şahin, 2017). Bu araştırmalar, öğretmen kalitesini ve öğretmenlerin gerçekleştireceği öğretimsel yaklaşımları ortaya koymak açısından önemlidir. Delice ve Sevimli (2010) öğretmen adaylarının belirli integral problemleri çözme sürecinde çoklu temsil kullanma becerilerini incelemiştir. Araştırmanın sonucunda tek bir temsil kullanarak çözüm üretmeye çalışan adayların temsil dönüştürme becerilerinin düşük olduğu, buna bağlı olarak problem çözme becerilerinin de zayıf olduğu sonucuna varmıştır. Benzer şekilde Çelik ve SağlamArslan (2012) öğretmen adaylarının sözel temsilden grafiğe geçişte yüksek başarı gösterdikleri; fakat şekilsel gösterimden grafiğe geçişte aynı başarıyı gösteremedikleri sonucuna ulaşmışlardır. İki çalışmada da öğretmen adaylarının çeşitli temsil geçişlerinde zorluklar yaşadıkları görülmektedir. Bunun yanında öğretmenlerin farklı temsilleri kullanabilme becerisi ve çoklu temsil destekli öğretim uygulamalarının incelenmesi üzerine gerçekleştirilen çalışmaların sınırlı olduğu görülmektedir (Çıkla, 2004; Eroğlu ve Tanışlı, 2015; Sevimli, 2009; Uçar, 2015). Eroğlu ve Tanışlı (2015) öğretmenlerin yanlış temsil içeren öğrenci cevaplarını yorumlamalarını ve verilen yanlış cevapların giderilmesine yönelik önerdikleri stratejilerini incelemiştir. Bu araştırmanın bulguları öğretmenlerin öğrenci temsil hatalarını yorumlamada ve önerdikleri strateji çeşitliliğinde yetersiz olduklarını ortaya çıkarmıştır. Geometri alanında gerçekleştirilen bir başka araştırmada ise Ahmetoğlu ve Aydın-Güç (2016) öğretmen adaylarının problem çözümlerinde çoğunlukla geometrik çözüm yolunu tercih ettiklerini belirtmiştir. Bu araştırmada, her problem sadece geometrik yolla çözülemeyeceğinden öğretmen adaylarının farklı çözüm yollarını tecrübe etmeleri gerektiğine vurgu yapılmıştır. Yapılan araştırmalar, gelecekte öğretmen olarak öğrencilerin öğrenmelerinden sorumlu olacak öğretmen adaylarının ve öğretmenlerin çoklu temsil kullanımı ve temsil geçişlerinde yeterli düzeyde olmadığı sonucunu ortaya koymuştur.

Alan yazında çoklu temsil destekli öğretimlerin öğrencilerin öğrenmesi üzerindeki etkilerini inceleyen araştırmalar, çoklu temsil destekli öğretimlerin öğrencilerin ilişkilendirme, soyut kavramları anlama, genelleme yapma ve modelleme becerilerini desteklediğini ortaya çıkarmıştır (Cihan, 2014; Çetin, 2016; Keller ve Hirsch, 1998). Çetin (2016) çalışmasında tamsayılar konusundaki çoklu temsil destekli öğretimin 6.sınıf öğrencilerinin başarısına etkisini araştırmış, çoklu temsil destekli öğrenen öğrencilerin geleneksel yöntemle öğrenenlere kıyasla daha başarılı oldukları sonucuna ulaşmıştır. Bu bağlamda, matematik öğretmenlerinden çoklu temsil kullanımını teşvik etmeleri ve öğrencilerinin kendi temsil yöntemlerini gösterecek öğrenme ortamları düzenlemeleri beklenmektedir (NCTM, 2000). Baştürk (2010) ise 9.sınıf öğrencilerinin fonksiyonlarda cebirsel sembolik temsil kullanımlarının sözel ve grafik temsil kullanımlarına kıyasla daha başarılı olduğunu ifade etmiştir. Farklı bir 
araştırmada da 9 ve 11. sınıf öğrencilerinin şekilli problemlerin çözümünde daha başarılı oldukları, şekilsiz problemlerin çözümünde ise kavramsal bilgi içeren şekli çizemedikleri ve prototip şekillerin etkisinde kaldıkları ortaya konulmuştur (Karpuz, Koparan ve Güven, 2014). Son olarak, Özhan-Turan (2011) çalışmasında analitik geometride 12.sınıf öğrencilerinin temsil geçişlerini düşünme yapılarını incelemiştir. Araştırmanın sonucunda farklı düşünme yapısındaki öğrencilerin öncelikle sorunun verildiği temsilden yararlanarak çözüm yapmaya çalıştığı ve en kısa yolu tercih ettikleri görülmüştür. Ayrıca cebirsel sembolik temsilden şekil temsiline ve diğer temsillerden cebirsel sembolik temsile geçişte başarının düşük olduğunu ortaya koymuşlardır. Bu araştırmanın sonucunda, sınıflarda farklı düşünme yapılarına sahip öğrencilerin bulunduğu gözetilerek, ders kitaplarının içeriğinin çoklu temsil biçimlerini içerecek şekilde tasarlanması gerekliliğine vurgu yapmışlardır.

Geometride temsil kullanımı üzerine yapılan çalışmaların, ders kitaplarındaki görsel öğelerin araştırılması üzerine yoğunlaştığı görülmektedir (Delice, Aydın ve Kardeş, 2010; Delice ve Sevimli, 2010; Uysal-Koğ, 2012). Delice ve Sevimli (2010), lise öğrencilerinin geometri problemlerini çözerken görsel kullanmadaki farklılıklarını araştırmış, öğrencilerin problem üzerindeki çizimlerini incelemişlerdir. Araştırma sonucunda problemlerin ifade edildiği temsil biçimlerinin, öğrencilerin çizim biçimlerini de etkilediği, öğrencilerin sözel temsile göre görsel temsilde daha başarılı olduklarını belirtmişlerdir. Araştırmanın bu sonucundan, öğrencilere ders kitaplarında sunulan girdi temsillerinin, onların başarılarını etkileyeceği çıkarılabilir. Ayrıca, İncikabı (2017) çalışmasında ortaokul matematik ders kitaplarındaki temsil çeşitlerini ve bu temsiller arasındaki geçişleri etkinlikler bağlamında analiz etmiştir. Araştırmasında ders kitaplarında en fazla cebirsel sembolik temsile yer verildiğini, bunun yanında sözel ve model temsilinin de yüksek oranda dağıldığını göstermiştir. Tablo, grafik ve günlük hayat temsillerine ise oldukça az yer verildiği görülmektedir. Bu araştırmada temsil geçişlerinin de en çok cebirsel, sözel ve model temsili arasında gerçekleştiği görülmektedir. Ayrıca problemlerin hem ifadesinde hem de çözümünde tablo, grafik ve günlük hayat temsillerinin kullanımının oldukça az olduğu ifade edilmiştir. Benzer şekilde Karakuzu (2017), çalışmasında ilk ve ortaokul ders kitaplarındaki geometri etkinliklerini incelemiştir. Bu incelemede tüm sınıf seviyelerinde en çok şekil temsiline yer verildiği bulgusuna ulaşıımıştır. Yine kitaplarda yer alan öğretimsel etkinliklerin ifade edilişinde de sembolik ve sözel temsilin oranının oldukça fazla olduğu belirtilmektedir. Alan-yazında özellikle ortaöğretim matematik ders kitaplarının geometri ünitelerinde kullanılan temsil türlerinin yer aldığı araştırma sonuçlarıyla ilgili bir boşluğun yer aldığı dikkat çekmektedir. Bu nedenle ortaöğretim geometri öğrenme alanına ait ders kitaplarında yer alan temsil türlerinin incelenmesini konu alan bir çalışmanın yapılması gerekliliği görülmektedir.

\section{Yöntem}

\section{Araştırmanın Amacı ve Problemleri}

Bu araştırmanın amacı, ortaöğretim 9. sınıf matematik ders kitabında üçgenler ünitesinde yer alan çözümlü ve çözümlü olmayan problemlerin girdi ve çıktı temsil türlerini incelemektir. Bu amaçla araştırmada aşă̆ıdaki problemlere yanıt aranmıştır:

1) 9. sınıf matematik ders kitabındaki üçgenler ünitesinde yer alan çözümlü problemlerin girdi ve çıktı temsillerinin dağııı oranları nasıldır?

2) 9. sınıf matematik ders kitabındaki üçgenler ünitesinde yer alan çözümlü olmayan problemlerin girdi temsillerinin dağılım oranları nasıldır?

3) 9. sınıf matematik ders kitabındaki üçgenler ünitesinde yer alan temsillerin konu bazlı dağılımı nasıldır?

\section{Araştırma Deseni ve Araştırma Materyali}


Matematik öğretimi üzerine geçmişten günümüze yapılan reformların en hızlı yansıması ders kitapları üzerine olmuştur. Çoklu temsiller matematiksel kavram ve bilgileri cümlelerle sözel temsil, tablolarla sayısal temsil, şekil ve diyagramlarla görsel temsil, matematiksel semboller yardımıyla cebirsel temsil olarak ilişkilendirmeyi sağlamaktadır. Böylece öğrenenler matematiği farklı şekillerde öğrenip geliştirebilirler (Choike, 2000). Bu araştırmada ortaöğretim 9. sınıf matematik ders kitabındaki problemler çoklu temsiller bağlamında incelendiğinden, araştırma doküman analizi olarak gerçekleştirilmiştir. Bowen (2009) doküman analizini, incelenecek belgelere araştırma konusunun çerçevesinde bir anlam vermek için araştırmacının yorumladığı nitel bir araştırma biçimi olarak tanımlamıştır. Ayrıca Yıldırım ve Şimşek de (2003) bu yöntemi araştııılması istenen verilere ilişkin bilgi sunan yazılı dokümanların analizi olarak ifade etmektedir. Bu araştırmanın amacı da var olan bir yazılı dokümanını -matematik ders kitabı- çoklu temsiller bağlamında incelemek olduğundan, araştırma yöntemi olarak doküman analizi uygun görülmüştür.

Araştırmada amaçlı örneklem yöntemlerinden ölçüt örnekleme yöntemi benimsenmiştir. Bu bağlamda araştırmada yıl, sınıf ve okutulduğu lise türü olmak üzere üç temel ölçüt belirlenmiştir. Belirlenen bu temel ölçütler doğrultusunda seçilen ve MEB Talim ve Terbiye Kurulu kararı ile 20202021 öğretim yılında tüm Türkiye'de fen liselerinde okutulan MEB yayınlarına ait "Ortaöğretim Fen Lisesi Matematik 9.sınıf Ders Kitabı" araştırmanın materyalini; kitapta yer alan üçgenler ünitesi ise araştırmanın verilerini oluşturmaktadır. Geometride yer alan üçgenler kavramı şekil ve sembolik temsile ek olarak, günlük hayat temsili, sözel temsil, somut materyal temsili gibi pek çok temsilin kullanımı için potansiyel taşıdığından dolayı bu konudaki problemlerin incelenmesi araştırmanın amacı için uygun görülmüştür. Bu noktadan hareketle, üçgenler ünitesinde bulunan çözümlü ve çözümlü olmayan problemler (sıra sizde ve alıştırma başlıklarında yer alan problemler) araştırma verisi olarak analiz edilmiştir. İncelenen kitabın kapak sayfası Ek-1'de yer almaktadır.

\section{Verilerin Analizi}

2020-2021 eğitim-öğretim yılında tüm Türkiye'de fen liselerinde okutulan 9.sınıf matematik ders kitabındaki çözümlü ve çözümlü olmayan problemler çoklu temsiller bağlamında içerik analizi kullanılarak incelenmiştir. İçerik analizi, iletişim içeriğinin insanların ürettikleri iletişim araçlarıyla (ders kitapları, yazılı metinler, gazeteler, dergiler fotoğraflar vb.) incelenmesine yarayan bir yöntemdir (Fraenkel, Wallen, ve Hyun, 2012). Bu araştırma da veriler matematik ders kitabındaki problemler ve bu problemlerdeki temsil biçimleri olduğundan içerik analizinin kullanımı uygun görülmüştür. Fraenkel vd. (2012) incelenecek içeriğin sınıflandırılmasını içerik analizinde kullanılabilecek yollardan biri olarak tanımlamaktadır. Analize başlamadan önce araştırmacılar tarafından incelenecek problemler ve problemlerde incelenecek temsil biçimlerinin kategorileri belirlenmiştir. İncelenecek problemlerin konu dağılımına göre frekansları Tablo 1'de sunulmuştur.

Tablo 1.

9.Sınıf matematik ders kitabında inceleme kapsamına alınan konular ve problem frekansları

\begin{tabular}{lcc}
\hline Konu Dağılımı & Çözümlü Problemler & Çözümlü Olmayan Problemler \\
\hline 9.4.1 Üçgenlerde Temel Kavramlar & 40 & 9 \\
9.4.2 Üçgenlerde Eşlik Benzerlik & 29 & 8 \\
9.4.3 Üçgenin Yardımcı Elemanları & 45 & 20 \\
9.4.4 Dik Üç̧gende Trigonometri & 27 & 21 \\
9.4.5 Üçgenin Alanı & 29 & 35 \\
\hline
\end{tabular}

Çalışmadaki temsil türlerinin incelenmesinde Kendall (2002), Goldin ve Kaput (1996) ve Lesh, Post ve Behr'in (1987) temsil sınıflamaları kullanılmıştır. Kitapta yer alan problemlerin tamamının 
birer dış temsil (Goldin ve Kaput, 1996) olduğu kabul edilerek sınıflamaya başlanmıştır. Ardından problemlerin ifade edilişlerinin birer girdi temsili olduğu (Kendall, 2002) ve çözümlü problemlerde yer alan çözümlerin ise çıktı temsili olduğu göz önünde bulundurulmuştur. Bu ayrıştırmanın ardından Lesh, Post ve Behr'in (1987) belirledikleri beş temsil türüne göre inceleme yapılmıştır. Lesh vd.'nin (1987) temsil türleri 1. sayılar-semboller, 2.sözlü temsiller, 3.gerçek hayat bağlamları, 4. manipülatif temsiller ve 5.resim, diyagram ve tablo temsilleri olarak ele alınmıştır. Bu çalışmada ders kitabındaki üçgenler ünitesinde yer alan problemlerde yer alan temsiller sembolik temsil, şekil temsili, sözel temsil ve günlük hayat bağlamı olarak ele alınmıştır. Ayrıca sembolik temsil 1. Geometrik ve 2. Cebirsel olarak iki alt kategori altında incelenmiştir. Burada geometrik sembolik temsil ile kastedilen, geometrik kavramlarda özel olarak kullanılan sembolik temsillerdir (örneğin açı gösterimi için kullanılan $\widehat{A B C}$ gibi). Tablo $1^{\prime}$ de frekans değerleri verilen tüm çözümlü ve çözümlü olmayan problemler belirtilen temsil biçimlerine göre kodlanmıştır. Problemler birden fazla temsil içerdiğinden girdi temsilleri 2 kategori, çıktı temsilleri 3 kategoride ele alınmıştır. Problemlerin içerdiği temsil biçimlerine ait örnek kodlamalar Tablo 2' de sunulmuştur.

Tablo 2.

Veri analizinde kullanılan analiz çerçevesi

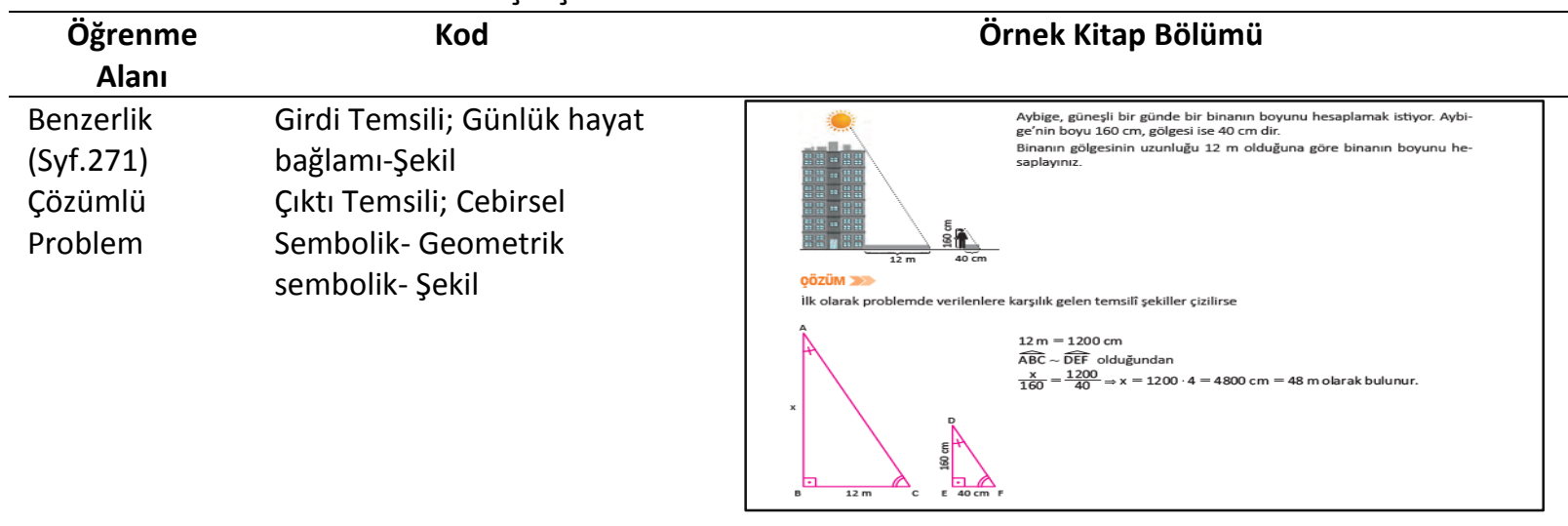

Üçgende Alan Girdi Temsili;

(Syf.350) Şekil-Geometrik

Çözümlü Sembolik

olmayan

problem

Üçgenlerde

Temel

Kavramlar

(Syf.228)

Çözümlü

Problem
Girdi Temsili; Sözel

Çıktı Temsili; Cebirsel

Sembolik-Şekil-Geometrik

Sembolik
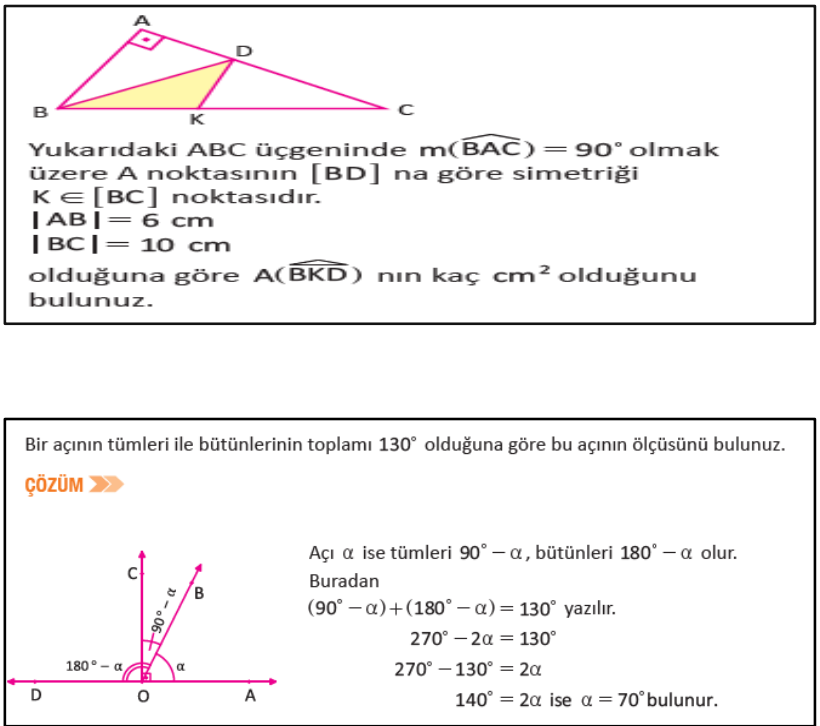

Veri analizinin bu aşamasında bağımsız çalışan iki kodlayıcı yer almıştır. Kodlayıcılar bağımsız olarak çözümlü/çözümlü olmayan problemleri tablodaki örnekleri temel alarak kodlamışlar ve sonrasında bu kodlamaları karşılaştırmışlardır. Kodlamaların güvenirliğini hesaplamak için Miles ve Huberman (1994) tarafından önerilen güvenirlik formülü [Güvenirlik=Görüş Birliği/(Görüş Birliği+Görüş Ayrılığı)] kullanıımıştır. Araştırmacıların kodlamalarına göre görüş birliğinde bulunulan 
kodların sayısı 162, görüş ayrılığında bulunulan kodların sayısı 22 olarak çıkmıştır. Bu verilere göre kodlayıcılar arasındaki güvenirlik kat sayısı 0,88 olarak hesaplanmıştır. Bu sonuç verilerin analizinin güvenirliğinin yüksek çıktığını göstermektedir (Miles ve Huberman, 1994). Son olarak araştırmacıların kodlamalarında görüş birliğine varamadıkları noktalarda, araştırma verilerinde tutarlılık sağlanması amacıyla ortak bir karara ulaşılmıştır. Kodlamaların bitiminin ardından, örneklerin ve kodlamaların güvenirliği için kodlayıcı araştırmacılar ve uzman bir matematik eğitimcisi bir araya gelerek veri analizini kontrol etmiştir. Analizlerin bitiminin ardından her bir problem için atanan öğrenme alanı, temsil türlerinin yüzde ve frekansları belirlenmiş ve bulguların sunumu için tablolar oluşturulmuştur.

\section{Araştırma Etik İzinleri}

Araştırmada ders kitabı araştırma materyali olarak kullanıldığından, araştırmada etik kurul onayını gerektirecek bir durum söz konusu değildir. Bu nedenle araştırma öncesinde herhangi bir kurumdan etik kurul onayı alınmamıştır.

\section{Bulgular}

Bu araştırmada ortaöğretim 9. sınıf ders kitabındaki üçgenler ünitesinde yer alan çoklu temsil türleri incelenmiştir. Araştırmanın bulguları 2 bölüm halinde sunulmuştur. illk bölümde üçgenler ünitesinde yer alan temsillerin dağılımı, ikinci bölümde ise bu temsillerin ünite içinde yer alan bölümlere göre dağılımı sunulmuştur.

Üçgenler ünitesinde ilk olarak konu dağılımları ve bu dağılımda yer alan çözümlü ve çözümsüz problemlerin incelemesi gerçekleştirilmiştir. Tablo 3'te üçgenler ünitesindeki konulara ve konular içerisinde yer alan örnek problem frekans değerlerine yer verilmiştir.

Tablo 3.

Üçgenler ünitesinde bulunan problemlerin konu dağııımına göre frekansları

\begin{tabular}{cccc}
\cline { 1 - 3 } Konu Dağılımı & Çözümlü Problemler & Çözümlü Olmayan Problemler & \\
\cline { 1 - 4 } 9.4.1 Üç̧genlerde Temel Kavramlar & 40 & 9 & çgenl \\
9.4.2 Üçgenlerde Eşlik Benzerlik & 29 & 8 & er \\
9.4.3 Üçgenin Yardımcı Elemanları & 45 & 20 & ünite \\
9.4.4 Dik Üçgende Trigonometri & 27 & 21 & si, \\
9.4.5 Üçgenin Alanı & 29 & 35 & Tablo \\
Toplam & 170 & 93 & 3'te \\
& & & görül \\
& & düğü
\end{tabular}

üzere 1. üçgenlerde temel kavramlar, 2. üçgenlerde eşlik benzerlik, 3. üçgenin yardımcı elemanları, 4. dik üçgende trigonometri ve 5 . üçgenin alanı olmak üzere beş bölümden oluşmaktadır. Bu bölümlerden üçgenlerde temel kavramlarda 40 çözümlü, 9 çözümlü olmayan problem, üçgenlerde eşlik benzerlikte 29 çözümlü, 8 çözümlü olmayan problem, üçgenin yardımcı elemanlarında 45 çözümlü, 20 çözümlü olmayan problem, dik üçgende trigonometride 27 çözümlü, 21 çözümlü olmayan problem ve üçgenin alanında ise 29 çözümlü, 35 çözümlü olmayan problem yer almaktadır. Bölümlerin genel yapısı incelendiğinde konu anlatım kısmına çok fazla yer verilmediği görülmüştür. Konuların anlatımı genel olarak kazanımlara ait örnekler ile gerçekleştirilmiş ve aynı kazanım altında benzer tipte çok sayıda problemin yer aldığı belirlenmiştir.

\section{Temsillerin Konu Bazlı Dağılımı}


Konular içerisinde yer alan problemler sözel, şekil, sembolik (geometrik ve cebirsel) ve günlük hayat bağlamı (GHB) olmak üzere beş temsil türüne göre incelenmiştir. Problemlerin ifadesinde yer alan temsiller girdi temsili ve problemlerin çözümlerinde kullanılan temsiller ise çıktı temsili olarak ele alınmıştır. Bu inceleme sonucunda elde edilen bulgular Tablo 4'te yer almaktadır.

Tablo 4.

Üçgenler ünitesinde yer alan temsillerin konu bazıı dağıııı (yüzde-\%)

\begin{tabular}{lccccccccccc}
\hline Konu & \multicolumn{2}{c}{ Sözel } & \multicolumn{2}{c}{ Şekil } & \multicolumn{2}{c}{$\begin{array}{c}\text { Geometrik- } \\
\text { Sembolik }\end{array}$} & \multicolumn{2}{c}{$\begin{array}{c}\text { Cebirsel- } \\
\text { Sembolik }\end{array}$} & \multicolumn{2}{c}{ GHB } \\
\hline & Girdi & Çıktı & Girdi & Çıktı & Girdi & Çıkı & Girdi & \multicolumn{1}{c}{ Çıtı } & Girdi & \multicolumn{1}{c}{ Çıtı } \\
\hline $\begin{array}{l}\text { 9.4.1 Üçgenlerde } \\
\text { Temel Kavramlar }\end{array}$ & 7,48 & 0 & 21,39 & 9,62 & 18,71 & 20,85 & 0 & 21,39 & 0,53 & 0 \\
$\begin{array}{l}\text { 9.4.2 Üçgenlerde } \\
\text { Eşlik ve Benzerlik }\end{array}$ & 0,68 & 0 & 25,17 & 10,20 & 19,72 & 19,72 & 0 & 19,72 & 4,76 & 0 \\
$\begin{array}{l}\text { 9.4.3 Üçgenin } \\
\text { Yardımcı }\end{array}$ & 0,39 & 0 & 24,70 & 14,50 & 24,70 & 17,64 & 0 & 17,2 & 0,39 & 0 \\
Elemanları & & & & & & & & & & \\
$\begin{array}{l}\text { 9.4.4 Dik Üçgende } \\
\text { Trigonometri }\end{array}$ & 0 & 0 & 24,20 & 10,82 & 24,20 & 17,19 & 0,63 & 16,56 & 6,36 & 0 \\
$\begin{array}{l}\text { 9.4.5 Üçgenin } \\
\text { Alanı }\end{array}$ & 2,34 & 0 & 22,56 & 14,02 & 25 & 17,68 & 0 & 17,68 & 0,60 & 0 \\
\hline
\end{tabular}

* Çözümlü ve çözümlü olmayan problemler girdi temsili olarak en fazla iki temsil, çözümlü problemlerin çıktı temsilleri en fazla üç temsil türü içermesine göre belirlenmiştir. Problemlerde birden fazla temsil türü kullanıldığından, her bir temsil türünün toplamı \%100'ü sağlamamaktadır.

Tablo 4'te yer alan bulgulara göre konu bazlı dağılımda en çok geometrik sembolik ve şekil temsillere yer verildiği ve tüm konularda temsillerin oran olarak \%31,01-\%42,68 aralığında yer aldığı görülmüştür. Dolayısıyla, problemlerde kullanılan temsil türlerinin, üçgenlerin alt konularında benzerlik gösterdiği ve farklı türlerde temsil çeşitlerinden ziyade şekil ve sembolik temsil başlığı altında toplandığı belirlenmiştir. Üçüncü sırada ise \%17,19-\%21,39 oranlarında cebirsel temsil yer almıs olup; bu temsil türünün de konulara göre farklılaşmadığı görülmüştür. Diğer bir ifadeyle, yukarıdaki bulgular incelendiğinde problemlerin girdi-çıktı temsillerinde sırasıyla en fazla sembolik, şekil ve cebirsel temsilin yer aldığı görülmektedir. Konu bazlı dağıımda farklılık sözel temsil ve günlük hayat bağlamında dikkat çekmektedir. Sözel temsil üçgenlerde temel kavramlar bölümünde diğer konulardan fazla yer alırken, günlük hayat bağlamı temsilinin en çok kullanıldığı konu dik üçgen ve trigonometri olmuştur. Sözel temsil oranları incelendiğinde ise üçgenlerde eşlik benzerlik, üçgenin yardımcı elemanları ve dik üçgenlerde trigonometri konularında bu temsil türüne çok az yer verildiği görülmüştür. Günlük hayat bağlamı temsiline de üçgenlerde temel kavramlar, üçgenin yardımcı elemanları ve üçgenin alanı konularında sadece birkaç problem içerisinde yer verilmiştir.

\section{Temsillerin Çözümlü ve Çözümlü Olmayan Problemler Bazında Dağılımı}

Temsillerin konu bazlı dağılımının incelenmesinin ardından problemler çözümlü ve çözümlü olmayan şeklinde ele alınmış ve yine analiz için belirlenmiş olan beş temsil türüne göre incelenmiştir. Çözümlü ve çözümlü olmayan problemlerin ifade edilişinde yer verilen temsil türleri girdi temsili olarak ele alınmıştır. Bu incelemede elde edilen bulgular Tablo 5'te yer almaktadır. 
Tablo 5.

9.sınıf üçgenler ünitesinde yer alan girdi temsillerin dağılımı (Yüzde-\%)

\begin{tabular}{ccc}
\hline Temsil Türü & $\begin{array}{c}\text { Çözümlü problemlerdeki girdi } \\
\text { temsilleri (\%) }\end{array}$ & $\begin{array}{c}\text { Çözümsüz problemlerdeki girdi } \\
\text { temsilleri (\%) }\end{array}$ \\
\hline Sözel & 5,59 & 1,78 \\
Şekil & 45,96 & 47,61 \\
Geometrik sembolik & 44,72 & 43,45 \\
Cebirsel sembolik & 0 & 0,59 \\
Günlük hayat bağlamı & 3,72 & 6,54 \\
\hline
\end{tabular}

Tablo 5'te yer alan bulgulara göre çözümlü problemlerdeki girdi temsillerinde en çok kullanılan temsil türü $\% 45,96$ oran ile şekil temsilidir. İkinci olarak problemlerin girdi temsillerinde geometrik sembolik temsile yer verilmiştir. Ünitedeki çözümlü problemlerdeki girdi temsillerinde sözel, cebirsel ve günlük hayat bağlamı türündeki temsillere çok az yer verildiği görülmektedir. Benzer şekilde çözümlü olmayan problemlerin girdi temsillerinde $\% 47,61$ oranla şekil ve $\% 43,45$ oranla geometrik sembolik temsilin yer aldığı görülmüştür. Bu durum çözümlü problemlerin girdi temsilleri ile benzerlik göstermektedir. Çözümlü olmayan problemlere benzer olarak, çözümlü problemlerin girdi temsilinde en az yer verilen temsil türleri sözel, cebirsel ve günlük hayat bağlamlarıdır. Bu bulgulara ek olarak, çözümlü problemlerin çıktı temsilleri de 5 farklı temsil türüne göre incelenmiştir. Bu başlık altında yer alan bulgular Tablo 6'da sunulmuştur.

Tablo 6.

9.Sınıf üçgenler ünitesinde yer alan çözümlü problemlerdeki çıktı temsillerin dağılımı (\%)

\begin{tabular}{cc}
\hline Temsil türü & Çıktı Temsillerinin Dağııımı \\
\hline Sözel & 0 \\
Şekil & 24,77 \\
Geometrik Sembolik & 37,72 \\
Cebirsel Sembolik & 37,5 \\
Günlük hayat bağlamı & 0 \\
\hline
\end{tabular}

Tablo 6'daki bulgular incelendiğinde, problemlerin çözümde en fazla geometrik sembolik ve cebirsel sembolik temsilin tercih edildiği ve bu temsillerin benzer oranda dağıldığı görülmektedir. Ünitede çözümlü problemlerin çıktı temsillerinde şekil temsilinin \%24,77 oranında kullanıldığı görülmektedir. Çözümlü problemlerde girdi temsilleri ve çıktı temsilleri kıyaslandığında girdi temsilinde daha çok şekil ve geometrik sembolik temsil kullanılırken, problemlerin çözümlerinde kullanılan çıktı temsillerinde en fazla geometrik sembolik ve cebirsel sembolik temsilin kullanıldığı görülmektedir. Problemlerin çözümünde yer verilen çıktı temsilerinde sözel temsile ve günlük hayat bağlamına hiç yer verilmediği görülmektedir.

\section{Tartışma, Sonuç ve Öneriler}

Ortaöğretim 9. sınıf matematik ders kitabında üçgenler ünitesinde yer alan temsillerin incelendiği bu araştırmada temel iki sonuca ulaşılmıştır. Araştırma sonucuna göre ortaöğretim 9. sınıf matematik ders kitabının üçgenler ünitesinde çözümlü ve çözümsüz problemlerin girdi temsillerinde en çok şekil ve geometrik sembolik temsile yer verildiği görülmüştür. Araştırma kapsamında incelenen diğer temsil türlerine ise -sözel, cebirsel sembolik ve günlük hayat bağlamı- çok az yer verildiği tespit edilmiştir. Çözümlü problemlerin çıktı temsillerinde ise en fazla geometrik sembolik ve 
cebirsel sembolik temsilin kullanıldığı, onlara göre daha az oranda şekil temsiline yer verildiği görülmüştür. Problem çözümlerinde sözel temsil kullanımına hiç yer verilmemiştir. Bu araştırma kapsamında incelenen ders kitabında temsillerin dağılımında ortaya çıkan durum alan yazında yer alan çalışmaların bulgularıyla örtüşmektedir (Alkhateeb,2019; İncikabı,2017; Inncikabı ve Biber, 2018). Alkhateeb (2019) çalışmasında Ürdün Eğitim Bakanlığının 8. Sınıf matematik ders kitabını temsiller bağlamında incelemiş ve kitabın farklı temsilleri içerecek şekilde oluşturulmadığını belirtmiştir. Benzer şekilde, İncikabı (2017) ortaokul ders kitaplarındaki temsil kullanımındaki dağılımın çeşitlendirilmediğini ifade etmiştir. Ders kitaplarında yer alan bu durumun öğrencilerin matematik öğrenmeleri üzerinde etkili olabileceği ve öğrencilerin temsil tercihlerini etkileyebileceği ifade edilmiştir (İncikabı, 2017). Öğrenmenin kavramsal olarak gerçekleşmesi için farklı temsillere yer verilen öğrenme ortamlarının önemi bilinmektedir (Adadan, 2013; Ainsworth,2006; Çelik ve SağlamArslan, 2012; Gagatsis ve Shikalli, 2004). Bu nedenle ders kitaplarında yer verilen temsillerin dağılımının belli temsillerde yoğunlaşmasının, öğrenmenin kavramsal düzeyde gerçekleşmesini ve öğrencilerin temsil tercihlerini olumsuz etkileyebileceği düşünülmektedir (Herman, 2002). Ayrıca matematik öğretimlerinde farklı temsillere yer verilmesinin öğrencilerin ilişkilendirme ve modelleme becerileri üzerindeki olumlu etkileri göz önüne alındığında, her öğrencinin kolayca ulaşabildiği ders kitaplarındaki temsil çeşitliliğinin sağlanması da oldukça önemlidir (Keller ve Hirsch, 1998).

Araştırmanın diğer bir sonucuna göre temsillerin konu bazlı dağııımında, girdi ve çıktı temsil durumunda sözel temsillerin dağılımındaki farklıık dikkat çekmektedir. Bütün konu türlerinde çıktı temsili olarak sözel temsile yer verilmediği görülmektedir. Bu durumun, problem çözümlerini sözel ifadelerle anlamlandırabilecek öğrenciler üzerinde olumsuzluk yaratacağı düşünülmektedir. Bir diğer sonuçta cebirsel-sembolik temsil girdi temsilinde oldukça düşük oranda kullanılmışken, çıktı temsilinde bu temsile çok fazla yer verilmiştir. Bu durumun öğrencileri cebirsel-sembolik temsilin yalnız çözümde kullanılacağı yönünde yanlış bir algıya sevk edebileceği ve öğrencilerin problemin ifade edilişinde cebirsel-sembolik temsili anlamlandırmalarını da etkileyebileceği düşünülmektedir. Ayrıca öğretim programlarımııın ve matematik otoritelerinin çoğunlukla üzerinde durduğu matematiği gerçek yaşamla ilişkilendirme becerisinin önemi bilinirken konu bazlı dağııımda görüldüğü gibi bazı konularda sınırı olmak koşuluyla günlük hayat bağlamı temsiline oldukça az yer verildiği görülmüştür. Bu durum öğretim programının istenilen hedefleriyle tezat bir durum oluşturmaktadır. Baki (1996) matematik müfredatının kapsadığı etkinliklerin günlük hayat ile ilişkilendirilmesinin, öğrencilerin matematiğe olan tutumlarını olumlu etkileyeceğini, böylece matematikle uğraşmanın bireyin günlük faaliyetlerinden biri olduğunu fark edebileceğini belirtmektedir. Ilgar ve ÇağırganGülten (2013) matematik ders kitaplarında matematiğin günlük hayatla ilişkilendirildiği içeriğe yeterince yer verilmesinin gerekliliğine vurgu yapmaktadır. Geometri -özellikle de üçgenler konusugünlük hayat ile ilişkilendirilebilecek en uygun alanlardan biridir. Ancak bu araştırmanın sonucunda ortaya çıkan günlük hayat problemleriyle ilgili durum, ders kitabındaki eksikliği ortaya koymaktadır. Ders kitaplarında yer alan günlük hayat ilişkilendirmelerindeki eksiliğin, öğrencilerin geometri konularını anlamlandırması ve günlük hayatla gerekli ilişkilendirmeleri yaparak problem çözme becerilerini geliştirmeleri konusunda engel olduğu düşünülmektedir.

Sonuç olarak, farklı temsil türlerinin girdi ve çıktı temsili olarak yer aldığı problemler ile kitabın içeriğinin zenginleştirilebileceği düşünülmektedir. Girdi temsilleri incelendiğinde problemlerin ifade edilişinde çoğunlukla şekil ve geometrik sembolik temsile yer verildiği, çıktı temsillerinde ise sözel, geometrik ve cebirsel sembolik temsillerin kullanıldığı görülmüştür. Bu durum özellikle girdi temsili olarak ele alındığında problemlerde günlük hayat temsiline çok az rastlanması ve çıktı temsillerinde ise sözel temsillere çok az yer verilmesi bir eksiklik olarak düşünülmektedir. Ders kitapları öğretim programının amaçları ve ders öğretimi arasında önemli bir geçiş aracıdır (Johansson, 2003). Ayrıca öğretim programlarının hedeflerinde sıklıkla yer alan farklı temsilleri kullanabilme ve matematiği günlük hayat ile ilişkilendirme hedeflerini etkili bir şekilde ele almayan ders kitaplarının etkili öğrenmede fayda sağlamadığı görülmektedir (Delice ve Sevimli, 2010; İncikabi, 2011). Bu 
araştırmanın sonuçlarının matematik öğretmen yetiştiricilerine, öğretmenlere ve ders kitabı yazarlarına 3 farklı noktada yol gösterici olduğu düşünülmektedir. Birinci nokta matematik öğretmen yetiştiricilerinin ders kitaplarında kullanılan temsillerdeki eksiklikler ve kitaplarda yer almasa dahi özellikle öğretimlerde çıktı temsili olarak pek çok temsile yer verilmesinin önemi konusunda öğretmen adaylarının farkındalıklarını arttırmaları gerektiği düşünülmektedir. İkinci nokta, öğretmenlerin ders kitaplarındaki temsillerle ilgili eksiklikler konusunda farkında olmaları ve bu eksikliği bilerek derslerinde bu eksiklikleri gidermek için temsillere ve temsiller arası geçişlere dayalı olarak öğretimlerini tasarlamaları önerilmektedir. Son olarak, yazarların temsil çeşitlerinin tamamından yararlanarak kitaplarının içeriklerini organize etmeleri gerekliliği ortaya çıkmaktadır. Araştırmacıların ise ortaokul ve lise ders kitaplarındaki farklı konuların çoklu temsiller bağlamında araştırma yapmaları önerilmektedir (İncikabı ve Biber, 2018). Çoklu temsiller her konu ve kavramın öğretiminde öğrencilere farklı şekillerde fırsatlar sunmaktadır. Bu yüzden farklı konularda gerçekleştirilecek çoklu temsil araştırmaları ile hangi konu ve kavramlarda hangi temsil türlerinin daha etkili öğrenmeyi sağladığının bilinmesi önemlidir. Bu tür araştırma sonuçlarının kitap içeriklerindeki çoklu temsilleri de etkileyeceği düşünülmektedir. Yapılacak araştırmalarda çoklu temsiller ile ilgili öğrenci çözümleri ve öğretmen görüşleri alınarak araştırmaların derinleştirilmesi sağlanabilir.

\section{Ek-1: Araştırmada veri materyali olarak kullanılan ders kitabının kapağı}

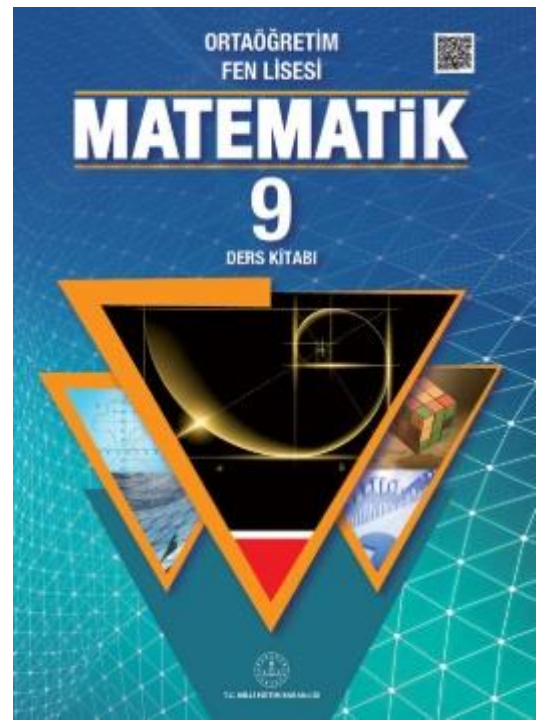




\section{Kaynakça}

Adadan, E. (2013). Using multiple representations to promote grade 11 students' scientific understanding of the particle theory of matter. Research in Science Education, 43(3), 1079-1105.

Adu-Gyamfi, K. (2007). Connections among representations: The nature of students coordinations on a linear function task. (Unpublished PhD). North Carolina State University, Mathematics Science And Technology Education, Raeligh.

Ahmetoğlu, F. ve Aydın-Güç, F. (2016). Illköğretim Matematik Öğretmeni Adaylarının Analitik Geometri Problemlerine Yönelik Çözüm Yaklaşımları. Necatibey Eğitim Elektronik Fen ve Matematik Eğitimi Dergisi, 10(1), 374-392.

Ainstworth, S. (2006). DeFT: A conceptual framework for considering learning with multiple representations. Learning and Instruction, 16(3), 183-198.

Altun, M., Arslan, Ç. ve Yazgan, Y. (2004). Lise matematik ders kitaplarının kullanım şekli ve sıklığı üzerine bir çalışma. Uludağ Üniversitesi Eğitim Fakültesi, 17(2), 131-147.

Alkhateeb, M. (2019). Multiple representations in 8th grade mathematics textbook and the extent to which teachers implement them. International Electronic Journal of Mathematics Education, 14(1), 137-145.

Anthony, G., \& Walshaw, M. (2009). Characteristics of effective teaching of mathematics: A view from the west. Journal of Mathematics Education, 2(2), 147-164.

Arslan, S., ve Özpınar, i. (2009). Illköğretim 6. sınıf matematik ders kitaplarının öğretmen görüşleri doğrultusunda değerlendirilmesi. Dicle Üniversitesi Ziya Gökalp Eğitim Fakültesi Dergisi, 12, 97-113.

Baştürk, S. (2007). Fonksiyon kavramının öğretiminin 9. sınıf ders kitapları bağlamında incelenmesi. Sakarya Üniversitesi Fen Edebiyat Dergisi, 9, 270-283.

Baştürk, S. (2010). Öğrencilerinin fonksiyon kavramının farklı temsillerindeki matematik dersi performansları. Gazi Eğitim Fakültesi Dergisi, 30(2), 465-482.

Bowen, G. A. (2009). Document analysis as a qualitative research method. Qualitative Research Journal, 9(2), 27-40.

Can, C. (2014). Fonksiyonlar konusunun çoklu temsiller ile öğretiminin öğrenci başarısına etkisinin incelenmesi. [Yayınlanmamış yüksek lisans tezi]. Balıkesir Üniversitesi, Ortaöğretim Fen ve Matematik Alanlar Eğitimi Anabilim Dalı, Balıkesir.

Çelik, D., ve Sağlam-Arslan, A. (2012). Öğretmen adaylarının çoklu gösterimleri kullanma becerilerinin analizi. Illköğretim Online, 11(1), 239-250.

Çetin, H. (2016). Sorgulayıcı öğrenme yaklaşımıyla çoklu temsil destekli tam sayı öğretiminin 6 . Sınıf öğrencilerinin başarılarına, model tercihlerine ve temsiller arası geçiş becerilerine etkisi. [Yayımlanmış doktora tezi]. Necmettin Erbakan Üniversitesi, Eğitim Bilimleri Enstitüsü, Matematik Eğitimi Bilim Dalı, Konya.

Çıkla-Oylum, A. (2004). The effects of multiple representations-based instruction on seventh grade students'algebra performance, attitude toward mathematics, and representation preference. [Unpublished doctoral dissertation]. Middle East Technical University, Ankara.

Choike, J. R. (2000). Teaching strategies for “Algebra for all”. Mathematics Teacher, 93(7), 556-560.

Delice, A., Aydın, E., ve Kardeş, D. (2009). Öğretmen adayı gözüyle matematik ders kitaplarında görsel öğelerin kullanımı. İstanbul Ticaret Üniversitesi Fen Bilimleri Dergisi, 16(2), 75-92.

Delice, A., ve Sevimli, E. (2010). Öğretmen adaylarının çoklu temsil kullanma becerilerinin problem çözme başarıları yönüyle incelenmesi: Belirli integral örneği. Kuram ve Uygulamada Eğitim Bilimleri, 10(1), 111-149.

Delice, A., \& Sevimli, E. (2016). Matematik eğitiminde çoklu temsiller. E. Bingölbali, S. Arslan, \& i.Ö. Zembat (Ed.), Matematik eğitiminde teoriler (ss. 519-537). Ankara: Pegem Akademi Yayıncılık.

Dienes, Z. P. (1960). Building up mathematics. London: Hutchinson Educational. 
Duval, R. (2006). A cognitive analysis of problems of comprehension in a learning of math-ematics. Educational Studies in Mathematics, 61, 103-131.

Eroğlu, D. ve Tanışlı, D. (2015). Ortaokul matematik öğretmenlerinin temsil kullanımına ilişkin öğrenci ve öğretim stratejileri bilgileri. Necatibey Eğitim Fakültesi Elektronik Fen ve Matematik Eğitimi Dergisi, 9(1), 275-307.

Fan, L. , Zhu, Y. , \& Miao, Z . (2013). Textbook research in mathematics education: Development status and directions. ZDM Mathematics Education, 45(5), 633-646.

Fraenkel, J. R., Wallen, N. E. ve Hyun, H. H. (2012). How to design ve evaluate research in education (8th Ed.). New York: McGraw Hill.

Fuson, K., Kalchman, M., \& Bransford, J. D. (2005). Mathematical understanding: An introduction. In M. S. Donovan \& J. D. Bransford (Eds.), How students learn: History, mathematics, and science in the classroom (pp. 217-256). Washington: National Academies Press.

Gagatsis, A., ve Shiakalli, M. (2004). Ability to translate from one representation of the concept of function to another and mathematical problem solving. Educational Psychology, 24(5), 645-657. https://doi.org/10.1080/0144341042000262953

Goldin, G. A., ve Kaput, J. J. (2013). A joint perspective on the idea of representation in learning and doing mathematics. In L. P. Steffe, P. Nesher, P. Cobb, B. Sriraman, \& B. Greer (Eds.), Theories of mathematical learning (pp. 409-442). New York: Routledge.

Goldin, G., \& Shteingold, N. (2001). Systems of representation and the development of mathematical concepts. In A. A. Cuoco \& F. R. Curcio (Eds.), The role of representation in school mathematics (pp. 1-23). Boston, Virginia: NCTM.

Haggarty, L., ve Pepin, B. (2002). An investigation of mathematics textbooks and their use in English, French, and German classrooms: Who gets an opportunity to learn what? British Educational Research Journal, 28(4), 567-590.

Hwang, W., Chen, N., Dung, J., \& Yang, Y. (2007). Multiple representation skills and creativity effects on mathematical problem solving using a multimedia whiteboard system. Educational Technology \& Society, 10(2), 191-212.

Herman, M. F. (2002). Relationship of college students' visual preference to use of representations: Conceptual understanding of functions in algebra. [Unpublished Doctoral dissertation]. The Ohio State University, Mathematics Education Graduate School of Ohio State University, Ohio.

Hiebert, J., \& Carpenter, T. P. (1992). Learning and teaching with understanding. In D. A. Grouws (Ed.), Handbook of research on mathematics teaching and learning: A project of the National Council of Teachers of Mathematics (pp. 65-97). Macmillan Publishing Co, Inc.

Işık, E. (2008). Predicting 9th grade students' geometry achievement: Contributions of cognitive style, spatial ability and attitude toward geometry. [Unpublished Master Thesis]. Middle East Technical University, Ankara.

Ilgar, L., ve Gülten, D. Ç. (2013). Matematik konularının günlük yaşamda kullanımının öğrencilere öğretilmesinin gerekliliği ve önemi. İstanbul Sabahattin Zaim Üniversitesi Sosyal Bilimler Dergisi, 2(3), 119-128.

Incikabi, L. (2011). Analysis of grades 6 through 8 geometry education in Turkey after the reform movement of 2004. [Unpublished Doctoral dissertation]. Columbia University, Teachers College, Columbia.

İncikabi, S. (2017). Çoklu temsiller ve matematik öğretimi: Ders kitapları üzerine bir inceleme. Cumhuriyet International Journal of Education, 6(1), 66-81.

Incikabı, S., ve Biber, A. Ç. (2018). Ortaokul matematik ders kitaplarında yer verilen temsiller arası ilişkilendirmeler. Kastamonu Eğitim Dergisi, 26(3), 729-740.

İskenderoğlu, T., ve Baki, A. (2011). İlköğretim 8. sınıf matematik ders kitabındaki soruların PISA matematik yeterlik düzeylerine göre sınıflandırılması. Eğitim ve Bilim, 36(161), 287-300. 
Janvier, C. (1987). Conceptions and representations: The circle as an example. In C. Janvier (Ed.), Problems of Representations in the Learning and Teaching of Mathematics (pp. 147-159). New Jersey: Lawrence Erlbaum Associates.

Johansson, M. (2003). Textbooks in mathematics education: A study of textbooks as the potentially implemented curriculum. [Unpublished doctoral dissertation]. Luleå tekniska universitet, Department of Arts, Communication and Education, Education, Luleå.

Kaput, J. J. (1992). Technology and mathematics education. In D. A. Grouws (Ed), Handbook of Research on Mathematics Teaching and Learning (pp. 515-556). New York: Macmillan Publishing.

Karakuzu, B. (2017). İlkokul ve ortaokul matematik ders kitaplarındaki geometri görevlerinin tür, bağlam, temsil biçimi ve bilişsel istem düzeyleri açısından incelenmesi. [Yayımlanmış Yüksek lisans Tezi]. Anadolu Üniversitesi, Eğitim Bilimleri Enstitüsü, Eskişehir.

Karpuz, Y., Koparan, T. ve Güven, B. (2014). Geometride öğrencilerin şekil ve kavram bilgisi kullanımı. Turkish Journal of Computer and Mathematics Education, 5(2),108-118.

Keller, B. A. ve Hirsch, C. R. (1998). Student preferences for representations of functions. International Journal in Mathematics Education Science Technology, 29(1), 1-17.

Kerpiç, A. ve Bozkurt, A. (2011). Etkinlik tasarım ve uygulama prensipleri çerçevesinde 7. Sınıf matematik ders kitabı etkinliklerinin değerlendirilmesi. Mustafa Kemal Üniversitesi Sosyal Bilimler Enstitüsü Dergisi, 8(16), 303-318.

Kendal, M. (2002). Teaching and learning introductory differential calculus. [Unpublished doctoral dissertation]. The University of Melbourne, Australia.

Kilpatrick, J., Swafford, J., ve Findell, B. (2001). Adding it up helping children learn mathematics. Washington: National Academy Press.

Konyalıoglu, A. C. (2003). Üniversite düzeyindeki vektör uzayları konusundaki kavramların anlaşılmasında görselleştirme yaklaşımının etkinliğinin incelenmesi. [Yayınlanmamış Doktora Tezi]. Atatürk Ünversitesi, Fen Bilimleri Enstitüsü, Erzurum.

Lesh, R., Post, T., ve Behr, M. (1987). Representations and translations among representations in mathematics learning and problem solving. In C. Janvier (Ed.), Problems of Representation in the Teaching and Learning of Mathematics (pp. 33-40). New Jersey: Lawrence Erlbaum Associates.

Miles, M. B., ve Huberman, A. M. (1994). Qualitative data analysis: An expanded sourcebook. London: Sage Publication.

Nakahara, T. (2007). Cultivating mathematical thinking trough representation. Paper presented at the APEC TSUKUBA International Conference, Tokyo, Kanazawa and Kyoto, Japan. Abstract retrieved from http://www.criced.tsukuba.ac.jp/math/apec/apec2008/index en.php.

National Council of Teachers of Mathematics (2000). Principles and standards for school mathematics. Reston, Va.: NCTM.

National Council of Teachers of Mathematics. (2014). Principles to actions. Reston, Va.: NCTM.

Özer, E., \& Sezer, R. (2014). A comparative analysis of questions in American, Singaporean, and Turkish mathematics textbooks based on the topics covered in 8th grade in Turkey. Educational Sciences: Theory and Practice, 14 (1), 411-421.

Özhan-Turan, A. (2011). 12. sınıf öğrencilerinin analitik geometrideki temsil geçişlerinin Krutetskii düşünme yapıları bağlamında incelenmesi: Doğruların birbirine göre durumları. [Yüksek Lisans Tezi]. Marmara Üniversitesi, Eğitim Bilimleri Enstitüsü, İstanbul.

Prain, V. ve Waldrip, B. (2010). Representing science literacies: An introduction. Research in Science Education, 40, 1-3. 
Sevimli, E. (2009). Matematik öğretmen adaylarının belirli integral konusundaki temsil tercihlerinin uzamsal yetenek ve akademik başarı bağlamında incelenmesi. [Yayımlanmamış yüksek lisans tezi]. Marmara Üniversitesi, Eğitim Bilimleri Enstitüsü, İstanbul.

Sevimli, E., ve Delice, A. (2012). The relationship between students' mathematical thinking types and representation preferences in definite integral problems. Research in Mathematics Education, 3(14), 295-296.

Şaban, I. H. (2019). Matematik ders kitapları cebir öğrenme alanındaki soruların PISA matematik yeterlik düzeylerine göre incelenmesi. [Yayımlanmamış yüksek lisans tezi]. Hacettepe Üniversitesi Eğitim Bilimleri Enstitüsü, Ankara.

Şahin, S., ve Turanlı, N. (2005). Liselerde okutulmakta olan lise I. sınıf matematik kitaplarının değerlendirilmesi. Gazi Üniversitesi Gazi Eğitim Fakültesi Dergisi, 25(2), 327-341.

Taşdemir, C. (2011). Ortaöğretim 10. sınıf matematik ders kitabının bazı değişkenler bakımından incelenmesi: Bitlis ili örneklemi. Karadeniz Fen Bilimleri Dergisi, 2(2), 41-54.

Tekin, A. T. (2007). Dokuzuncu ve on birinci sınıf öğrencilerinin zihinde döndürme ve uzamsal görselleştirme yeteneklerinin karşılaştırmalı olarak incelenmesi. [Yayınlanmamış Yüksek Lisans Tezi]. Ankara Üniversitesi, Eğitim Bilimleri Enstitüsü, Ankara.

Uğurel, I., Bukova-Güzel, E. ve Kula, S. (2010). Matematik öğretmenlerinin öğrenme etkinlikleri hakkındaki görüş ve deneyimleri. Buca Eğitim Fakültesi Dergisi, 28, 103-123.

Uçar, Z. T. (2015). Ortaokul matematik öğretmen adaylarının reel sayıları kavrayışlarına temsillerin etkisi. Kastamonu Education Journal, 24(3), 1149-1164.

Uysal Koğ, O. (2012). Görselleştirme yaklaşımı ile yapılan matematik öğretiminin öğrencilerin bilişsel ve duyuşsal gelişimi üzerindeki etkisi. [Yayımlanmamış doktora tezi]. Dokuz Eylül Üniversitesi, Eğitim Bilimleri Enstitüsü, İzmir.

Yang, D., Tseng, Y., ve Wang, T. (2017). A comparison of geometry problems in middlegrade mathematics textbooks from Taiwan, Singapore, Finland, and the United States. Eurasia Journal of Mathematics, Science, and Technology Education, 13(7), 2841-2857.

Yeşildere-İmre, S., Akkoç, H., ve Baştürk-Şahin, B. N. (2017). Ortaokul öğrencilerinin farklı temsil biçimlerini kullanarak matematiksel genelleme yapma becerileri. Turkish Journal of Computer and Mathematics Education, 8(1), 103-129.

Yıldırım, A. ve Şimşek, H. (2003). Sosyal bilimlerde nitel araştırma yöntemleri. Ankara: Sözkesen Matbaacılık. 